\title{
Disease Expression and Molecular Genotype in Congenital Adrenal Hyperplasia due to 21-Hydroxylase Deficiency
}

\author{
Phyllis W. Speiser, * Jakob Dupont, * Deguang Zhu, * Jorge Serrat, * Miriam Buegeleisen, * Maria-Teresa Tusie-Luna, * \\ Martin Lesser, ${ }^{\star}$ Maria I. New, ${ }^{*}$ and Perrin C. White* \\ * Department of Pediatrics, Division of Pediatric Endocrinology, Cornell University Medical College, New York 10021; and ${ }^{\ddagger}$ Division of \\ Biostatistics, North Shore University Hospital-Cornell University Medical College, New York 10021
}

\begin{abstract}
Genotyping for 10 mutations in the CYP21 gene was performed in 88 families with congenital adrenal hyperplasia due to $21-h y-$ droxylase deficiency. Southern blot analysis was used to detect CYP21 deletions or large gene conversions, and allele-specific hybridizations were performed with DNA amplified by the polymerase chain reaction to detect smaller mutations. Mutations were detected on $95 \%$ of chromosomes examined. The most common mutations were an $\mathbf{A} \rightarrow \mathbf{G}$ change in the second intron affecting pre-mRNA splicing (26\%), large deletions $(21 \%)$, Ile-172 $\rightarrow$ Asn (16\%), and Val-281 $\rightarrow$ Leu (11\%). Patients were classified into three mutation groups based on degree of predicted enzymatic compromise. Mutation groups were correlated with clinical diagnosis and specific measures of in vivo 21-hydroxylase activity, such as 17-hydroxyprogesterone, aldosterone, and sodium balance. Mutation group A (no enzymatic activity) consisted principally of salt-wasting (severely affected) patients, group B ( $2 \%$ activity) of simple virilizing patients, and group C (10-20\% activity) of nonclassic (mildly affected ) patients, but each group contained patients with phenotypes either more or less severe than predicted. These data suggest that most but not all of the phenotypic variability in 21-hydroxylase deficiency results from allelic variation in CYP21. Accurate prenatal diagnosis should be possible in most cases using the described strategy. (J. Clin. Invest. 1992. 90:584-595.) Key words: steroid 21-hydroxylase deficiency • CYP21 • allelic variation
\end{abstract}

\section{Introduction}

Congenital adrenal hyperplasia due to 21-hydroxylase deficiency is among the most common inborn errors of metabolism. Steroid 21-hydroxylase is a microsomal cytochrome P450 required for synthesis of cortisol and aldosterone but not for synthesis of sex steroids ( 1 ). The gene encoding the active adrenal 21-hydroxylase, CYP21, has been characterized $(2,3)$. Located on the short arm of chromosome 6 in the midst of the class III HLA region, the gene is closely linked to the highly polymorphic genes encoding HLA-B and DR $(4,5)$. Mutations in the CYP21 gene are almost always either deletions (6) or transfers of deleterious sequenes $(7,8)$ from the adjacent pseudogene, CYP21P, to the active gene, CYP21, in a process termed gene conversion $(9,10)$.

Address correspondence to Dr. Phyllis W. Speiser, Room N236, New York Hospital-Cornell University Medical College, 525 East 68th Street, New York, NY 10021.

Received for publication 5 December 1991 and in revised form 21 February 1992.

J. Clin. Invest.

(c) The American Society for Clinical Investigation, Inc.

$0021-9738 / 92 / 08 / 0584 / 12 \$ 2.00$

Volume 90, August 1992, 584-595
There are three major disease phenotypes. In the classic salt-wasting form, both cortisol and aldosterone synthesis are severely impaired; adrenal overproduction of androgen precursors leads to pre- and postnatal virilization, which is most apparent in affected female newborns with ambiguous external genitalia. In the classic simple virilizing form, cortisol synthesis is impaired, but aldosterone synthesis is normal to elevated (11); these patients also undergo pre- and postnatal virilization. In the nonclassic form, a subtle defect in cortisol synthesis can often only be detected during stimulation with corticotropin; aldosterone synthesis is normal and adrenal-derived androgen precursors are moderately elevated (12). In females with the nonclassic form of 21-hydroxylase deficiency, prenatal virilization is not observed.

The molecular genetic basis of this disease has been thoroughly investigated (for reviews see references 9 and 10). Table I provides a summary of the known mutations, their prevalence, and effects upon enzyme activity as determined by in vitro mutagenesis and expression. The strongest associations reported to date have been deletion of CYP21 in patients with the salt-wasting form (13-16) and a point mutation in the seventh exon, which results in a conservative amino acid substitution, Val-281 $\rightarrow$ Leu, in patients with the nonclassic form of 21-hydroxylase deficiency (17). The most frequent non-deletional mutation found in classic patients is a point mutation in the second intron, which activates an aberrant splice acceptor site (18); this mutation has been detected in patients affected with either the salt-wasting or simple virilizing forms of the disease $(19,20)$

In this report, we genotyped a large number of affected patients and members of their nuclear families for deletions and nine other discrete CYP21 mutations, allowing assignment of specific mutations to the respective maternal and paternal chromosomes. Patients were categorized into one of three mutation groups depending on degree of predicted enzymatic compromise and clinical and hormonal statuses were retrospectively examined. We sought to determine how closely the predicted behavior of various CYP21 mutations was reflected by in vivo measures of 21-hydroxylase deficiency in each of the three adrenal zones. Conversely, we asked whether the clinician could be expected to predict the genotype based on the clinical diagnoses of salt-wasting, simple virilizing, or nonclassic 21 -hydroxylase deficiency. Thorough clinical evaluation of patients genotyped in this study suggests that most but not all of the phenotypic variability in 21-hydroxylase deficiency results from allelic variation in CYP21.

\section{Methods}

Patients. A total of 88 families of diverse ethnic backgrounds were studied. In 90 patients from 79 of these families, CYP21 mutations were identified on each of the two chromosomes. Clinical data are 
Table I. Functional Mutations in CYP21 and Activity of Expressed Mutant 21-Hydroxylase Enzyme

\begin{tabular}{|c|c|c|c|c|}
\hline Designation & Site & $\begin{array}{l}\text { Prog/ } \\
170 H P \\
\text { NL Activity }\end{array}$ & Function & Allele frequency (reference)* \\
\hline & & $\%$ & & \\
\hline \multicolumn{5}{|c|}{ Group A: No enzyme activity } \\
\hline Deletion & Exons 1-8 & $0 / 0$ & No gene product & $\begin{array}{l}20 \%(6) ; 33 \%(13) ; 35 \%(14) ; 11 \% \\
\quad(16) ; 19 \%(20)\end{array}$ \\
\hline Del 8 bp & Exon 3 & $0 / 0$ & Frameshift; no activity & $3-10 \%(7,18-20) ; 1 \%(36)$ \\
\hline Cluster & Exon 6 & $0 / 0$ & & $17 \%(20) ; 3 \%(36)$ \\
\hline \multicolumn{5}{|l|}{ Ile236 $\rightarrow$ Asn } \\
\hline \multicolumn{5}{|l|}{ Val237 $\rightarrow$ Glu } \\
\hline \multicolumn{5}{|l|}{ Met239 $\rightarrow$ Lys } \\
\hline $\begin{array}{l}\text { Phe306 } \\
\text { Insert T }\end{array}$ & Exon 7 & $0 / 0$ & $\begin{array}{l}\text { Termination before heme- } \\
\text { binding site }\end{array}$ & $1 \%(36)$ \\
\hline Gln $318 \rightarrow$ term & Exon 8 & $0 / 0$ & $\begin{array}{l}\Delta \text { mRNA stability; termination } \\
\text { before heme-binding site }\end{array}$ & $3-7 \%(8,18,19)$ \\
\hline $\operatorname{Arg} 356 \rightarrow \operatorname{Trp}$ & Exon 8 & $0 / 0$ & $? \Delta$ Substrate binding & $14 \%(36)$ \\
\hline bp656 A $\rightarrow G$ & Intron 2 & $?$ & Activates new splice acceptor & $42 \%(19) ; 26 \%(20) ; 31 \%(36)$ \\
\hline \multicolumn{5}{|c|}{$\begin{array}{l}\text { Group B: Severely impaired } \\
\text { enzyme activity }\end{array}$} \\
\hline Ile $172 \rightarrow$ Asn & Exon 4 & $2 / 2$ & $? \Delta \mathrm{ER}$ membrane orientation & $5-10 \%(7)(19)(20)$ \\
\hline \multicolumn{5}{|c|}{$\begin{array}{l}\text { Group C: Moderately } \\
\text { impaired enzyme activity }\end{array}$} \\
\hline Pro30 $\rightarrow$ Leu & Exon 1 & $30 / 60$ & $? \Delta \mathrm{ER}$ membrane orientation & $17 \%$ (32) (NC patients only) \\
\hline Val281 $\rightarrow$ Leu & Exon 7 & $20 / 50$ & $? \Delta$ Tertiary structure & $84 \%$ (20) (B14+ NC patients) \\
\hline
\end{tabular}

* Allele frequencies are from studies in classic patients unless otherwise stated.

tabulated only for patients from the latter group. Five patients had been previously reported as completely genotyped. Patients were born between 1949 and 1991; 74\% were regularly treated at The New York Hospital-Cornell University Medical College (NYH-CUMC), and $59 \%$ were followed at our institution from infancy or early childhood. Medical records and laboratory tests were thoroughly reviewed for those patients not diagnosed in our institution. To assign the CYP21 mutations to maternal and paternal haplotypes, patients were preferentially selected from families where both mother and father were available for study. Thus, both parents were genotyped in 67 families, in 10 additional families one parent was genotyped, and in the remaining 2 families the patient's child was genotyped, allowing assignment of the patient's two mutations to each of his two chromosomes. HLA-B14 homozygotes were excluded to avoid including an excessive number of Val-281 $\rightarrow$ Leu homozygotes.

Hormone assays. Adrenocortical steroid hormones in serum were measured by radioimmunoassay (21-23). Patients were diagnosed according to published reference data derived from this laboratory (24) by measuring the basal and/or corticotropin-stimulated serum 17-hydroxyprogesterone in the absence of glucocorticoid treatment. Urinary aldosterone was measured as the acid-hydrolyzable conjugate, aldosterone-18-glucuronide (25). This metabolite of aldosterone represents a constant percentage of secreted aldosterone $(26,27)$. Plasma renin activity (PRA) ${ }^{1}$ was determined by the method of Sealey and Laragh with modifications (28).

Phenotype evaluation. Two methods were used to assess disease severity. First, the clinical diagnosis of salt-wasting, simple virilizing, or nonclassic disease was assigned by the primary pediatric endocrinologist (M. I. New for patients diagnosed and treated at NYH-CUMC) based on history, physical examination, presence or absence of electro-

1. Abbreviation used in this paper: PRA, plasma renin activity. lyte abnormalities, and hormonal data. Genital ambiguity in females was graded according to the scale of Prader (29). Patients who had overt evidence of sodium depletion, i.e., hyponatremia, hyperkalemia, dehydration, and/or shock (adrenal crisis), were classified as salt wasting, and among them basal serum 17-hydroxyprogesterone, where available, was usually $>500 \mathrm{nmol} /$ liter. Those with no evidence of sodium depletion, but markedly elevated basal and corticotropin-stimulated 17-hydroxyprogesterone levels (usually $>300 \mathrm{nmol} /$ liter), were said to have simple virilizing disease. Nonclassic patients had lower levels of 17-hydroxyprogesterone and no evidence of prenatal virilization (12).

Presence or absence of adrenal salt-wasting crisis and basal sodium and potassium levels were recorded at the time of diagnosis. When the medical records indicated that there had been no electrolyte abnormalities the serum sodium and potassium were recorded as normal in the phenotype score. Efficiency of the adrenal zona glomerulosa in synthesizing aldosterone, a function dependent on 21-hydroxylase, was determined in selected patients by measuring the ratio of PRA/urinary aldosterone-18-glucuronide standardized for body surface area. Higher ratios of PRA to aldosterone were assumed to be, at least in part, reflective of increasingly severe 21 -hydroxylase deficiency. These studies were always performed with adequate glucocorticoid replacement (dexamethasone, $2 \mathrm{mg} / \mathrm{d}$ for $\geq 2 \mathrm{~d}$, or hydrocortisone, $15-30 \mathrm{mg} / \mathrm{m}^{2}$ per d chronically), no mineralocorticoid supplements, and under conditions of dietary sodium deprivation $(10 \mathrm{mmol} / \mathrm{d}$ for $2-5 \mathrm{~d})$. The majority of patients studied were over the age of $5 \mathrm{yr}$. Sodium balance, expressed as total daily sodium excretion divided by intake (thus, the higher the number, the more negative the sodium balance), was recorded for the same period. Several patients were studied at two different ages.

Because several of our patients did not precisely fit all criteria for one of these three categorical clinical diagnoses, we used a second mode of phenotype evaluation: an objective rating scale was devised to in- 


\begin{tabular}{|c|c|c|c|c|}
\hline & \multicolumn{4}{|c|}{ Phenotype score } \\
\hline & 0 & 1 & 2 & 3 \\
\hline Serum $\mathrm{Na}(\mathrm{mM})$ & $\mathrm{Na} 135-145$ & $\mathrm{Na} 125-134$ & $\mathrm{Na}<125$ & \\
\hline Serum K (mM) & K 3.5-5 & K 5-6 & $K>6$ & \\
\hline PRA/ALDO & $<1$ & $1-10$ & $>10,<50$ & $\geq 50$ \\
\hline Na BALANCE & $\leq 1$ & $1-4$ & $\geq 4$ & \\
\hline $170 H P 0^{\prime}(\mathrm{nM})$ & $<3$ & $3-30$ & $>30-300$ & $>300$ \\
\hline $170 \mathrm{OP} 60^{\circ}$ & $<6$ & $6-60.5$ & $60.5-605$ & $>605$ \\
\hline P'triol $(\mu \mathrm{mol} / \mathrm{d})$ & $<3$ & $3-15$ & $15-30$ & $>30$ \\
\hline Genitalia (Prader) & $\mathrm{nl}$ & $1-2$ & 3 & $4-5$ \\
\hline
\end{tabular}

Score $=$ total point score/number of data points available $\times 100$.

For each parameter listed, a subscore of 0 indicates a normal value, and disease severity increases as subscores and total score increase. A maximal subscore of 2 (serum Na, serum K, Na balance) or 3 (PRA/ALDO, 17OHP, P'triol, and Prader score) indicates a severely abnormal value. As an example of phenotype score calculation, patient 1 in mutation group A1 (Table V) received a subscore of 2 each for serum $\mathrm{Na}$ and $\mathrm{K}$ of 117 and $10 \mathrm{mmol} /$ liter, respectively; PRA/ALDO of 3.7 yielded a subscore of 1 ; Na balance of 2.4 warranted a subscore of 1 ; the Prader score was 4 , for which she received a phenotype subscore of 3 . Thus, patient 1 had an adjusted total phenotype score of 9 based on five available data points: $(9 \div 5) \times 100=180$.

clude the several measures of the in vivo expression of 21-hydroxylase deficiency (Table II) described above. The total score for each individual was divided by the number of data points available and multiplied by 100 ; only patients with four or more data points were included in the statistics. For patients diagnosed in the years before the advent of radioimmunoassay for serum 17-hydroxyprogesterone, 24-h urinary pregnanetriol measurements were recorded. Both the clinical diagnosis and the phenotype score were compared with the patients' genotypes.

Genotype evaluation. Peripheral blood leukocyte DNA samples were obtained as described (30). An alternative protocol that avoids phenol extraction ( 31 ) was used in a minority of samples.

Southern blot analysis. This procedure was performed as described (6), using the restriction enzymes Taq I and Bgl II to determine CYP2 1 gene copy number. Deletions of CYP21 were identified by the absence (or by decreased intensity in heterozygotes) of the Taq I 3.7-kb and Bgl II 12-kb hybridizing bands. Large gene conversions were detected by the absence or decreased intensity of the 3.7-kb Taq I fragment without any apparent abnormality in the Bgl II digest. To identify smaller mutations not detectable by Southern blotting, the following procedures were employed:

(i) Polymerase chain reaction. Genomic DNA was amplified in two segments by the polymerase chain reaction using primers that selectively amplify CYP21, not the highly homologous CYP21P gene (19) (Fig. 1). Fragment 1 represents a 677-bp segment extending from exon 1 (primer sequence 5'-TGGAACTGGTGGAAGCTCCGG-3') through the 8-bp deletion in exon 3 (primer sequence $5^{\prime}$-AGCAGGGAGTAGTCTCCCAAG-3'; underlined nucleotides represent the 8-bp deletion typically found in CYP21P). Fragment 2 is an $\sim 1.5-$ $\mathrm{kb}$ fragment extending from the 8-bp deletion in exon 3 (primer sequence $5^{\prime}$-TTGTCCTTGGGAGACTACTCC-3') through the eighth intron (primer sequence 5'-GCTCGGGCTTTCCTCACTCAT-3'). Amplification reactions were carried out as described (32).

(ii) Allele-specific oligonucleotide probe hybridizations. Serial hybridizations were performed with end-labeled, allele-specific normal and mutant oligonucleotide probes (32) representing point mutations that may be introduced into CYP2 1 from CYP21P by gene conversion (Table III; Fig. 1). The presumption was made that DNA samples that amplified with both sets of polymerase chain reaction primers did not have a homozygous gene conversion involving the 8-bp deletion in the third exon. A heterozygous gene conversion within the third exon was suspected if a patient was apparently homozygous for a given mutation, but only one parent was heterozygous for the mutation. Homozygous gene conversion at the 8-bp deletion was suspected if DNA from the patient failed to amplify, yet Southern blot analysis showed a normal restriction pattern in both parents. These unusual cases were further analyzed by constructing separate CYP21-specific oligonucleotide primers not centered on the 8-bp deletion (20). Mutations were designated $\mathrm{A}, \mathrm{B}$, or $\mathrm{C}$ according to decreasing order of severity as described below (see Results; Tables IV and V).

Statistical analysis. Differences between basal and stimulated $17-$ hydroxyprogesterone levels among mutation groups $\mathrm{A}, \mathrm{B}$, and $\mathrm{C}$ were detected using the Kruskal-Wallace test. Analysis of variance was used to assess differences in phenotype score between mutation groups. Discriminant analysis (PROC DISCRIM; SAS Institute Inc., Cary, NC) was used to classify patients into each of the three mutation groups based on the phenotype score or clinical diagnosis. Classification cutoff points were computed from this analysis. Classification error rates were computed based on prior probabilities that were equal to the observed proportions of each of the three mutation groups. Since several patients' phenotype scores were outliers, the discriminant analysis was also performed using a rank transformation. The 56 individuals with four or more data points for phenotype score were ranked from 1 to 56 (with midranks assigned to tie scores) and these ranks were used as the dependent variable in the analysis. Cut-off points were computed for

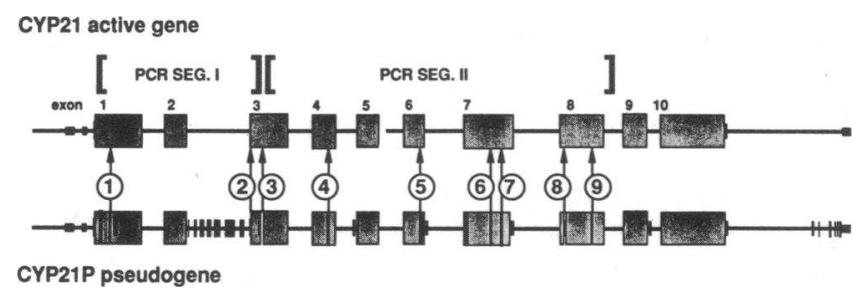

Figure 1. Functional CYP21 mutations and PCR amplification strategy. Sequence differences between the CYP21P pseudogene and CYP21 active gene known to cause clinical 21-hydroxylase deficiency are shown by the circled numbers: 1 , exon 1 , Pro-30 $\rightarrow$ Leu; 2 , intron $2 \mathrm{~A} \rightarrow \mathrm{G}$; 3, exon 3, 8-bp deletion; 4, exon 4, Ile-172 $\rightarrow$ Asn; 5, exon 6 , cluster of mutations (Ile-236 $\rightarrow$ Asn; Val-237 $\rightarrow$ Glu; Met-239 $\rightarrow$ Lys); 6, exon 7, Val-281 $\rightarrow$ Leu; 7, exon 7, Phe $306+T$; 8, exon 8 , Gln-318 $\rightarrow$ term; 9, exon 8, Arg-356 $\rightarrow$ Trp. Other vertical lines represent differences between CYP21P and CYP21 that are apparently not functionally significant. The CYP21 active gene was specifically amplified in two segments as described in text. 
Table III. Oligonucleotide Probes Used in Hybridization Analysis of Patient Samples

\begin{tabular}{|c|c|}
\hline Designation & Sequence \\
\hline P30 wild type & 5'-CTCCACCTCCCGGCCTCTTGCC-3' \\
\hline P30L mutant & $5^{\prime}$-CTCCACCTCCTGCCTCTTGCC-3' \\
\hline bp656-A wild type & 5'-AGCCCCCAACTCCTCCTGCA-3' \\
\hline bp656-G mutant & 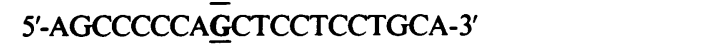 \\
\hline I172 wild type & 5'-TGCAGCATCATCTGTTACCTC-3' \\
\hline I172N mutant & 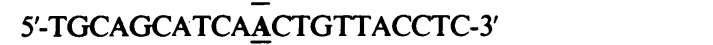 \\
\hline I236/V237/M239 wild type & 5'-AGGGATCACA产CGTGGAGATGCAGCTGAGG-3' \\
\hline I236N/V237E/M239K mutant & 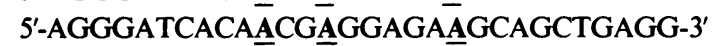 \\
\hline V281 wild type & 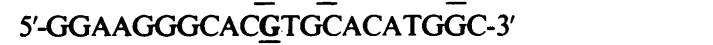 \\
\hline V281L mutant & 5'-GGAAGGGCACTTGCACATGGC-3' \\
\hline F306 wild type & 5'-GGTGAAGCAAĀAAAACCACGGCC-3' \\
\hline INSERT p F306 mutant & 5'-GGTGAAGCAAAAAAAACCACGGCC-3' \\
\hline Q318 wild type & 5'-CAGCGACTGCĀGGAGGAGCTA-3' \\
\hline Q318ter mutant & 5'-CAGCGACTGT̄AGGAGGAGCTA-3' \\
\hline R356 wild type & 5'-CTGCGCCTGĒGGCCCGTTGTG-3' \\
\hline R356W mutant & 5'-CTGCGCCTGT̄GGCCCGTTGTG-3' \\
\hline
\end{tabular}

Bases underlined in boldface represent differences between wild type and mutant probes.

the ranks, and then the ranks were "inverted" to yield the corresponding cut-off point in phenotype score units.

\section{Results}

Phenotypic evaluation. By clinical diagnosis, a total of 53 saltwasting, 25 simple virilizing, and 12 nonclassical patients were studied. The distribution of salt-wasting versus simple virilizing classic patients is compatible with the $\sim 2-3: 1$ proportion expected based on the results of newborn screening programs and case surveys (33). Nonclassic patients were deliberately underrepresented in this study because of previously published data demonstrating that the Val-281 $\rightarrow$ Leu mutation found in association with the HLA-B14,DR1 haplotype accounts for $\sim 75-80 \%$ of nonclassic mutations $(17,20)$.

Table IV. Mutation Groups of Patients with 21-hydroxylase Deficiency

\begin{tabular}{llcrc}
\hline Group & \multicolumn{1}{c}{ Mutations } & $\begin{array}{c}\text { Possible } \\
\text { genotype } \\
\text { combinations }\end{array}$ & $n$ & $\begin{array}{c}\text { Clinical } \\
\text { diagnosis }\end{array}$ \\
\hline A $_{1}$ & DEL & $\mathrm{A}_{1} / \mathrm{A}_{1}$ & 47 & SW \\
& DEL Ex 3 & $\mathrm{A}_{1} / \mathrm{A}_{2}$ & 5 & SV \\
& Cluster Ex 6 & $\mathrm{A}_{2} / \mathrm{A}_{2}$ & & \\
& Phe-306 $\rightarrow+\mathrm{T}$ & & & \\
& Gln-318 $\rightarrow$ term & & & \\
& Arg-356 $\rightarrow$ Trp & & & \\
$\mathrm{A}_{2}$ & Int 2 & & & \\
$\mathrm{B}$ & Ile-172 $\rightarrow$ Asn & A/B & 4 & SW \\
& & B/B & 16 & SV \\
& & & 2 & NC \\
C & Val-281 $\rightarrow$ Leu & A/C & 2 & SW \\
& Pro-30 $\rightarrow$ Leu & B/C & 4 & SV \\
& & C/C & 10 & NC \\
& & & & \\
\hline
\end{tabular}

$\mathrm{NC}$, nonclassic; SV, simple virilizing; SW, salt wasting.
All females with the salt-wasting form of the disease had both clitoromegaly and urogenital sinus, Prader stage III-V, requiring corrective surgery. Females affected with simple virilizing disease had clitoromegaly, but did not necessarily have a urogenital sinus, and were classed as Prader stage II-IV. Mild clitoromegaly, or Prader stage I, and slight webbing of the labia minora were the only signs of genital virilization in females affected with the nonclassic form of 21-hydroxylase deficiency.

All patients had elevated serum 17-hydroxyprogesterone measurements (24) and/or urinary pregnanetriol $>8 \mu \mathrm{mol} / \mathrm{d}$; however, levels measured during treatment were not recorded here or used in the statistical analysis. Classic 21-hydroxylasedeficient patients had basal serum 17-hydroxyprogesterone levels ranging from 151 to $2604 \mathrm{nmol} /$ liter in the absence of glucocorticoid replacement therapy. Basal 17-hydroxyprogesterone levels were significantly higher in salt-wasting compared with simple virilizing patients (mean \pm SD: $1,239 \pm 719$ vs. $526 \pm 412 \mathrm{nmol} /$ liter, $P=0.002$ ). There was one patient classified as salt-wasting with basal serum 17-hydroxyprogesterone level $<200 \mathrm{nmol} /$ liter in the neonatal period. All other defects of steroid biosynthesis had been excluded. This patient had severe electrolyte derangements and subsequently had a 17-hydroxyprogesterone level above $400 \mathrm{nmol} /$ liter while on treatment during a period of stress.

Patients affected with the nonclassic disorder had 60-min corticotropin-stimulated serum 17-hydroxyprogesterone levels that were statistically different from those of classic simple virilizing patients (mean \pm SD: $324 \pm 167$ vs. $1,217 \pm 433 \mathrm{nmol} /$ liter, $P=0.003$ ).

The ratio of plasma renin activity ( $\mathrm{ng} /$ liter per s) to aldosterone 18-glucuronide $\left(\mathrm{nmol} / \mathrm{m}^{2}\right.$ per $\mathrm{d}$ ) under conditions described above ranged from three to infinitely high (ratio arbitrarily designated 100 in Table V) among young salt-wasting patients, with the normal ratio being maximally 0.1 in sodiumdeprived healthy adults (34). One sibling pair studied at ages 30 and 36 yr showed relatively low PRA/aldosterone ratios. All but one patient categorized as salt wasting showed evidence of hyponatremia, hyperkalemia, and / or hypovolemic shock in 
Table V. Phenotype and Genotype in 21-Hydroxylase-deficient Patients by Group

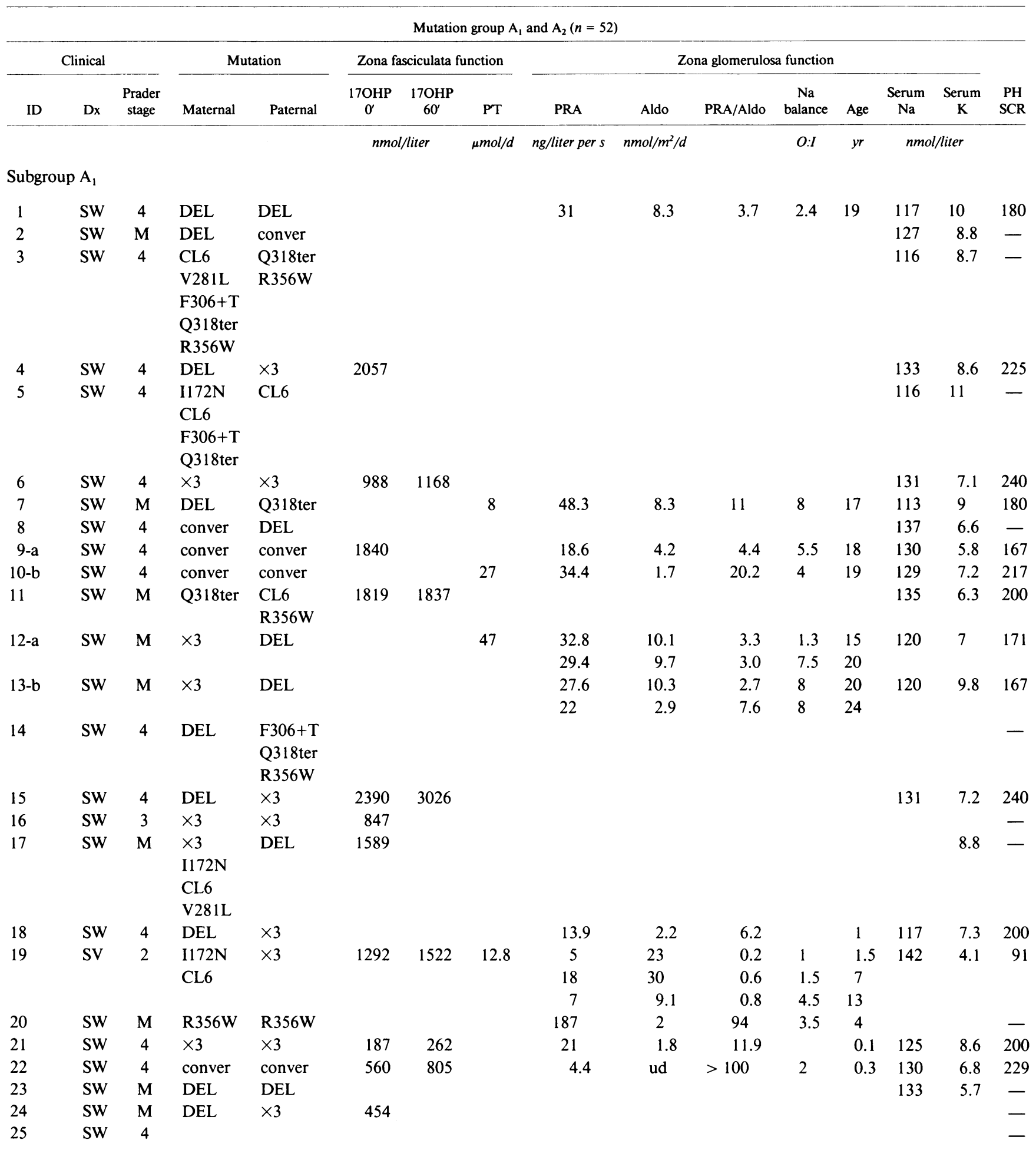

Sub-Group A2

\begin{tabular}{|c|c|c|c|c|c|c|c|c|c|c|c|c|c|c|}
\hline 26 & SV & $\mathbf{M}$ & R356W & i2 & 1579 & 1846 & 20.1 & 30.3 & 0.7 & 1 & 3 & 135 & 6 & 117 \\
\hline 27 & SW & na & i2 & DEL & & & & & & & & & & - \\
\hline \multirow[t]{2}{*}{$28-a$} & SW & 4 & DEL & i2 & & & 6.7 & 0.4 & 18.8 & 1.7 & 13 & 118 & 5.9 & 171 \\
\hline & & & & & & & 20.3 & 3.8 & 5.3 & 4 & 19 & & & \\
\hline $29-b$ & SW & $\mathbf{M}$ & DEL & i2 & & & 42 & 1 & 42 & 7 & 28 & 134 & 7.2 & 175 \\
\hline 30 & SW & 4 & i2 & DEL & 817 & & & & & & & 126 & 8.4 & 225 \\
\hline 31 & SW & 5 & i2 & i2 & & & & & & & & 123 & 8.4 & - \\
\hline
\end{tabular}




\begin{tabular}{|c|c|c|c|c|c|c|c|c|c|c|c|c|c|c|c|}
\hline \multicolumn{16}{|c|}{ Mutation group $A_{1}$ and $A_{2}(n=52)$} \\
\hline \multicolumn{3}{|c|}{ Clinical } & \multicolumn{2}{|c|}{ Mutation } & \multicolumn{3}{|c|}{ Zona fasciculata function } & \multicolumn{7}{|c|}{ Zona glomerulosa function } & \multirow[b]{2}{*}{$\begin{array}{c}\text { PH } \\
\text { SCR }\end{array}$} \\
\hline ID & Dx & $\begin{array}{l}\text { Prader } \\
\text { stage }\end{array}$ & Maternal & Paternal & $\underset{\sigma}{17 \mathrm{OHP}}$ & $\begin{array}{c}17 \mathrm{OHP} \\
60^{\circ}\end{array}$ & PT & PRA & Aldo & PRA/Aldo & $\begin{array}{c}\mathrm{Na} \\
\text { balance }\end{array}$ & Age & $\begin{array}{c}\text { Serum } \\
\mathrm{Na}\end{array}$ & $\underset{\mathbf{K}}{\text { Serum }}$ & \\
\hline & & & & & \multicolumn{2}{|c|}{ nmol/liter } & $\mu \mathrm{mol} / \mathrm{d}$ & ng/liter per $s$ & $\mathrm{nmol} / \mathrm{m}^{2} / \mathrm{d}$ & & $O: I$ & $y r$ & nmol & /liter & \\
\hline 32 & SW & 4 & i2 & i2 & & & & 1.2 & ud & $>100$ & 0.1 & 15 & 129 & 6.2 & 180 \\
\hline 33 & SW & $\mathbf{M}$ & i2 & i2 & 1490 & & & & & & & & 115 & 9.3 & - \\
\hline 34 & SV & $\mathbf{M}$ & i2 & $\times 3$ & 218 & 608 & & 5.6 & 125 & 0.05 & 0.8 & 2 & 137 & 4.7 & 83 \\
\hline 35 & SW & 4 & $\mathrm{i} 2$ & DEL & & & 6 & & & & & & 134 & 9.8 & 175 \\
\hline 36 & SW & na & DEL & i2 & 523 & & & & & & & & & 8 & - \\
\hline $37-a$ & SW & $\mathbf{M}$ & DEL & i2 & & & & 60.6 & 3.3 & 18.4 & 2 & 2 & 118 & 8.2 & 175 \\
\hline $38-b$ & SW & $\mathbf{M}$ & DEL & i2 & & & & 6 & ud & $>100$ & 1.3 & 7 & 132 & 5.8 & 150 \\
\hline 39 & SW & $\mathbf{M}$ & $\mathrm{i} 2$ & DEL & & & & 91 & 13.4 & 6.8 & 1 & 0.8 & 114 & 8 & 125 \\
\hline 40 & SW & $\mathbf{M}$ & i2 & i2 & 1029 & & & & & & & & 116 & 8 & - \\
\hline 41 & SW & $\mathbf{M}$ & i2 & $\times 3$ & & & & & & & & & 116 & 12 & - \\
\hline 42 & SW & $\mathbf{M}$ & DEL & i2 & 2604 & & 8.5 & 15 & 0.7 & 21 & 1 & 4 & 130 & 9.6 & 160 \\
\hline 43 & SW & $\mathbf{M}$ & i2* & conver & 680 & 797 & & & & & & & 120 & 12 & 250 \\
\hline 44 & SW & 4 & $\mathrm{i} 2$ & $\times 3$ & & & & & & & & & 117 & 10 & - \\
\hline 45 & SW & $\mathbf{M}$ & i2 & DEL & & & & & & & & & 111 & 7.6 & 175 \\
\hline 46 & SV & 4 & Q318ter & i2 & 387 & 957 & & 22.5 & 28.3 & 0.8 & 3 & 7 & 137 & 4.1 & 143 \\
\hline 47 & SW & 4 & i2 & i2 & 1936 & & & 27 & 5.4 & 5 & 3 & 1 & 129 & 6 & 167 \\
\hline $48-a$ & SW & 4 & i2 & DEL & & & & 6.1 & 74.9 & 0.1 & 7.7 & 36 & 127 & 5.5 & 140 \\
\hline 49-b & SW & 4 & i2 & DEL & & & & 8 & 5.5 & 1.5 & 1 & 30 & 124 & 6.6 & 160 \\
\hline 50 & SW & 5 & i2 & i2 & & & & & & & & & 130 & 9 & - \\
\hline 51 & SV & 3 & i2 & i2 & & & & & & & & & 140 & 4 & - \\
\hline 52 & SW & $\mathbf{M}$ & DEL & i2 & & & & & & & & & 113 & 8 & - \\
\hline Mean & & & & & 1242 & 1282 & & & & & & & & & 177 \\
\hline SD & & & & & 724 & 803 & & & & & & & & & 42 \\
\hline Median & & & & & 1160 & 1062 & & & & & & & & & 175 \\
\hline Q3-Q1 & & & & & 1210 & 1040 & & & & & & & & & 40 \\
\hline
\end{tabular}

\begin{tabular}{|c|c|c|c|c|c|c|c|c|c|c|c|c|c|c|c|}
\hline \multicolumn{16}{|c|}{ Mutation group $\mathrm{B}(n=22)$} \\
\hline \multirow[t]{2}{*}{1} & SV & $\mathbf{M}$ & CL6 & $\mathrm{I} 172 \mathrm{~N}$ & & & & & & & & & 140 & 3.8 & 一 \\
\hline & & & & V281L & & & & & & & & & & & \\
\hline 2 & SV & $\mathbf{M}$ & i2 & $1172 \mathrm{~N}$ & & & & 19 & 14 & 1.4 & 1.8 & 4 & 137 & 4.5 & 50 \\
\hline 3 & SV & 4 & conver & $1172 \mathrm{~N}$ & 303 & & & & & & & & $\mathrm{nl}$ & $\mathrm{nl}$ & 150 \\
\hline 4 & SW & 3 & R356W & $1172 \mathrm{~N}$ & 440 & & & & & & & & 135 & 6.8 & 175 \\
\hline 5 & SV & 3 & $\mathrm{I} 172 \mathrm{~N}$ & i2 & & & & & & & & & $\mathrm{nl}$ & $\mathrm{nl}$ & - \\
\hline 6 & SW & 4 & $1172 \mathrm{~N}$ & DEL & & & 40 & 37 & 12.3 & 3 & 0.6 & 0.3 & 132 & 7.9 & 167 \\
\hline 7 & SV & $\mathbf{M}$ & $1172 \mathrm{~N}$ & i2 & & & & & & & & & $\mathrm{nl}$ & $\mathrm{nl}$ & - \\
\hline 8-a & NC & 1 & $1172 \mathrm{~N}$ & Q318ter & 64 & & & & & & & & $\mathrm{nl}$ & $\mathrm{nl}$ & 75 \\
\hline $9-b$ & SV & 2 & I172N & Q318ter & 389 & 728 & & & & & & & 143 & 6.5 & 180 \\
\hline $10-\mathbf{a}$ & SV & $\mathbf{M}$ & DEL & $1172 \mathrm{~N}$ & 269 & 1221 & & & & & & & 141 & 4.8 & 125 \\
\hline $11-b$ & SV & $\mathbf{M}$ & DEL & $1172 \mathrm{~N}$ & 555 & 1534 & & 8 & 61 & 0.1 & 0.1 & 1.4 & 141 & 4.6 & 100 \\
\hline \multirow[t]{2}{*}{12} & SV & 3 & $1172 \mathrm{~N}$ & $1172 \mathrm{~N}$ & 605 & & & & & & & & 139 & 5.3 & 150 \\
\hline & & & CL6 & & & & & & & & & & & & \\
\hline 13 & SV & $\mathbf{M}$ & Q318ter & I172N & & & & 16 & 22.2 & 0.7 & 3.3 & 31 & $\mathrm{nl}$ & $\mathrm{nl}$ & 25 \\
\hline 14 & SV & 3 & I1 $72 \mathrm{~N}$ & R356W & & & & & & & & & $\mathrm{nl}$ & $\mathrm{nl}$ & - \\
\hline 15 & SV & $\mathbf{M}$ & i2 & I172N & & & 74 & & & & & & $\mathrm{nl}$ & $\mathrm{nl}$ & - \\
\hline 16 & SV & 3 & i2* & $1172 \mathrm{~N}$ & & & & 9 & 55.3 & 0.2 & 2 & 2 & $\mathrm{nl}$ & $\mathrm{nl}$ & 60 \\
\hline 17 & SV & 3 & I172N & conver & & & & & & & & & $\mathrm{nl}$ & $\mathrm{nl}$ & - \\
\hline $18-\mathrm{a}$ & SV & 4 & i2 & $1172 \mathrm{~N}$ & 151 & & & & & & & & $\mathrm{nl}$ & $\mathrm{nl}$ & 125 \\
\hline $19-b$ & $\mathrm{NC}$ & $\mathbf{M}$ & $\mathrm{i} 2$ & I172N & 38 & & & & & & & & $\mathrm{nl}$ & $\mathrm{nl}$ & - \\
\hline \multirow[t]{2}{*}{20} & SW & 4 & DEL & $1172 \mathrm{~N}$ & & & & 0.7 & ud & $>100$ & - & 0.1 & 132 & 6.2 & 217 \\
\hline & & & & & & & & 94 & 9 & 10.4 & 5 & 12 & & & \\
\hline 21 & SV & $\mathbf{M}$ & $1172 \mathrm{~N}$ & DEL & 481 & 727 & & 12 & ud & $>100$ & 1 & 2 & $\mathrm{nl}$ & $\mathrm{nl}$ & 150 \\
\hline 22 & SW & 4 & $I 172 \mathrm{~N}$ & I172N & & & & & & & & & 125 & 6.8 & - \\
\hline
\end{tabular}




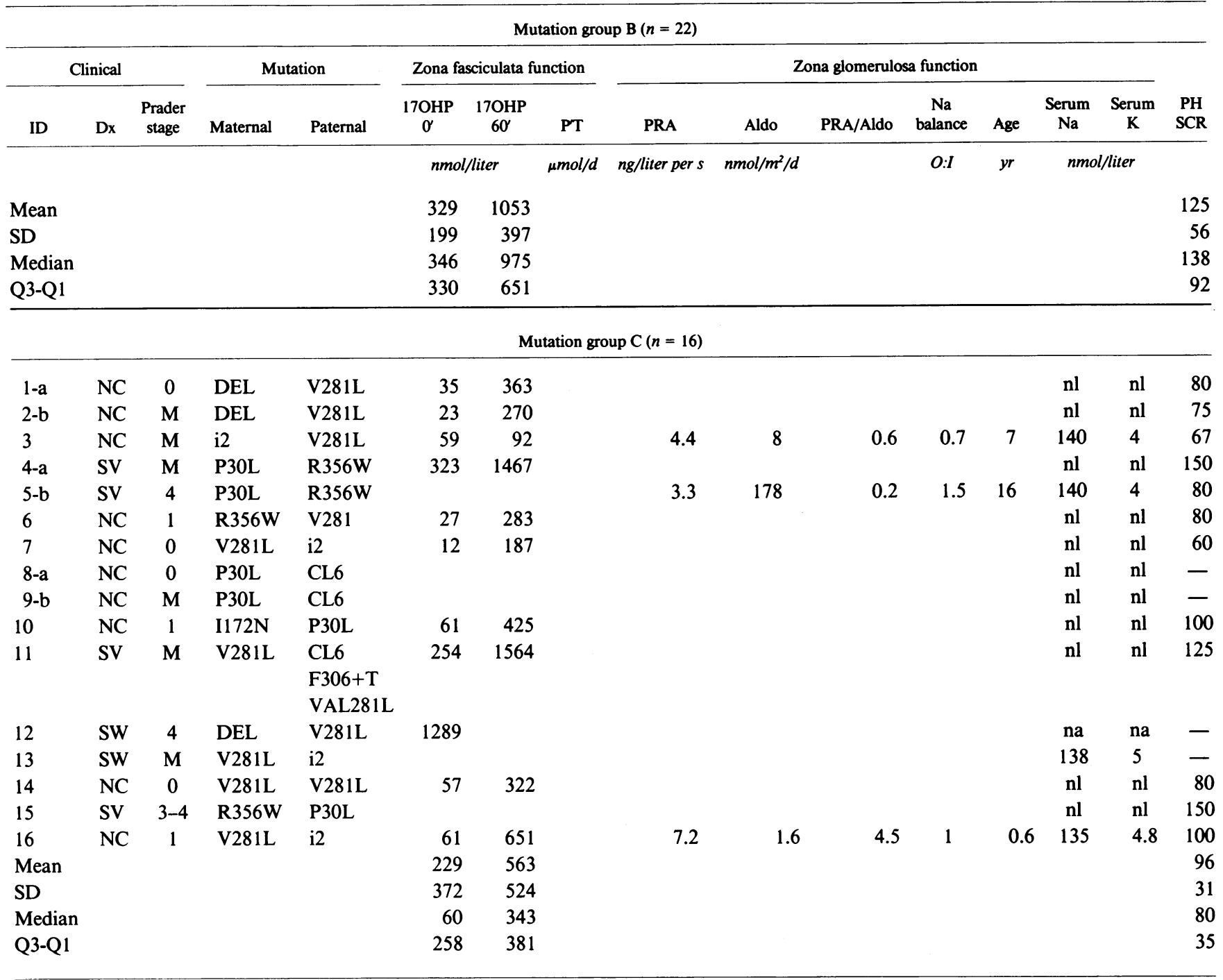

In patient ID column, a and b indicate siblings. Under Dx, SW refers to salt-wasting patient, SV to simple virilizing, and NC to nonclassic patients. Prader stage for genital ambiguity is given where known for female patients; males are designated $M$. Description of the various mutations may be found in Table $I$ : group $A$ (including subgroups $A_{1}$ and $A_{2}$ ) are mutations and genotype combinations conferring no enzyme activity; genotype combinations in group $B$ confer severely impaired enzyme activity; and genotype combinations group $C$ confer moderately impaired enzyme activity. Mutation nomenclature in Table V: Deletion, DEL; large gene conversion detectable on Southern blot, conver; deletion of 8 bp in exon 3, $\times 3$; cluster of three mutations in exon 6, CL6; Phe306, insert T, F306+T; Gln318 $\rightarrow$ term, Q318ter; Arg356 $\rightarrow$ Trp, R356W; intron 2 bp656 A $\rightarrow$ G, i2; Ile172 $\rightarrow$ Asn, I172N; Pro30 $\rightarrow$ Leu, P30L; Val281 $\rightarrow$ Leu, V281L. De novo mutations are indicated by asterisks. Serum 17-hydroxyprogesterone is given before and $60 \mathrm{~min}$ after corticotropin stimulation; P'T indicates basal 24-h urinary pregnanetriol. PRA (plasma renin activity), Aldo (urinary aldosterone-18-glucuronide, ud signifies undetectable), and the ratio of PRA/aldosterone and sodium balance were measured under conditions described in Methods ( $>100$ indicates a ratio that was infinitely high). Age refers to the patients' age at the time of the PRA/aldo and sodium balance study. Serum electrolytes represent the nadir of $\mathrm{Na}$ and peak $\mathrm{K}$ at presentation. The method of calculating phenotype score is described in text. Descriptive statistics are given for 17-hydroxyprogesterone and phenotype score.

early life. Neither simple virilizing nor nonclassic patients, who were less frequently studied for aldosterone synthesis, had concomitant hyponatremia and hyperkalemia typical of salt-wasting patients. Two simple virilizing and one nonclassic patient had high PRA/aldosterone ratios in early childhood.

Genotype evaluation. Results of previously published in vitro mutagenesis and expression studies $(18,32,35,36)$ were used to predict the degree of enzyme deficiency for each mutation (Table I). The predicted enzymatic activity for conversion of 17-hydroxyprogesterone to 11-deoxycortisol of the most se- vere mutation on each of the patient's two chromosomes was calculated (Table IV). For instance, homozygous deletion, or deletion in trans with a stop mutation, or the cluster of mutations at exon 6, all of which confer zero enzyme activity in vitro (35), would be predicted to result in $0 \%$ overall 21 -hydroxylase activity in vivo. This type of patient would be categorized in group $A$, subgroup $1\left(A_{1}\right)$. A deletion conferring zero enzyme activity on the product of the maternal gene in combination with an intron $2 \mathrm{~A} \rightarrow \mathrm{G}$ mutation, or homozygotes for the intron 2 mutation, were categorized in group A, subgroup 2 
$\left(A_{2}\right)$. Homozygotes carrying the mutation Ile-172 $\rightarrow$ Asn, which confers $\sim 2 \%$ of normal activity on the gene product $(35,36)$, as well as compound heterozygotes for any of the group A mutations in trans with the Ile-172 $\rightarrow$ Asn mutation, were categorized as group B. Homozygotes for milder mutations, such as Val-281 $\rightarrow$ Leu and Pro-30 $\rightarrow$ Leu, which have $\sim 50 \%$ of wild-type enzymatic activity for conversion of 17 hydroxyprogesterone to 11-deoxycortisol in vitro $(35,36)$ ( $20 \%$ for progesterone to deoxycorticosterone), would be categorized in group C. Similarly, the combination of either of the latter mutations with Ile-172 $\rightarrow$ Asn ( $2 \%$ activity) or group A mutations ( $0 \%$ activity) would place the patient in group $\mathrm{C}$ with an average of $\sim 25 \%$ normal predicted enzymatic function for conversion of 17-hydroxyprogesterone to 11-deoxycortisol ( $\sim 10 \%$ for progesterone to deoxycorticosterone).

Overall, mutations were detected on $95 \%$, or 171 / 182 chromosomes examined (data not shown for patients in whom the mutation on one chromosome was not identified). When analyzed in this manner, $\sim 74 \%$ of chromosomes were classified as bearing group A mutations. Large deletions comprised 19\% of all chromosomes, large gene conversions (mutations in three or more contiguous exons) $5 \%$, and intron 2 mutations $25 \%$. Approximately $13 \%$ of mutations were found in group B, and $7 \%$ were found in group $\mathrm{C}$. In $5 \%$ of chromosomes examined, no mutations were detected using this methodology.

Relationship of mutation group to clinical diagnosis. A total of 25 patients ( 23 families) were homozygous for mutations in group $A_{1}$, which result in no enzyme activity; all but one patient in this group had salt-wasting disease (Tables IV and V). 27 additional patients in group $A_{2}$ (24 families) were homozygous for the intron 2 mutation or were compound heterozygotes for a group $A_{1}$ mutation in trans with the intron 2 mutation. All but one of seven patients homozygous for the intron $2 \mathrm{~A} \rightarrow \mathrm{G}$ mutation had salt-wasting disease; none of the seven has been studied beyond adolescence. 3 of 20 compound heterozygotes for the intron 2 mutation were simple virilizing patients with normal or mildly elevated PRA/aldosterone ratios (0.04-0.8) and no evidence of electrolyte derangements; the remainder were salt wasting.

22 patients ( 19 families) were categorized as Group B. Four were diagnosed as salt wasting, 16 were simple virilizing, and 2

\section{MO PT FA}

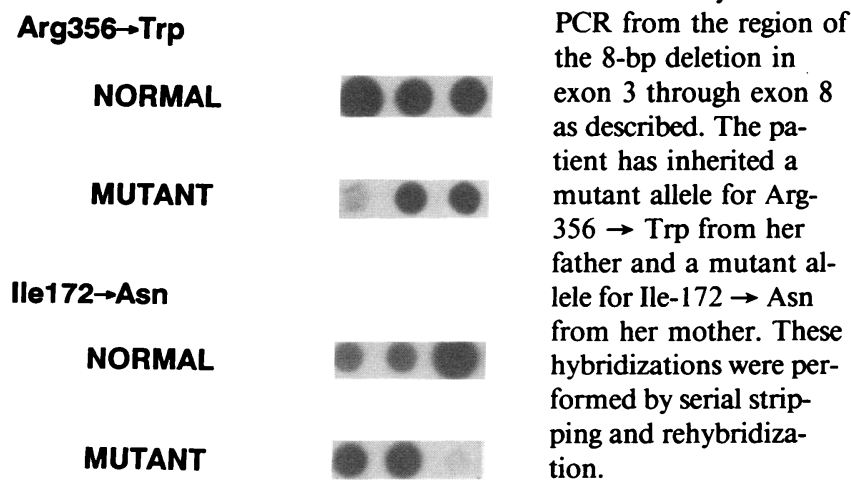

were nonclassic patients. One female with the genotype combination deletion/Ile-172 $\rightarrow$ Asn had severe, unremitting saltwasting disease. A prototypic result of allele-specific hybridization in a patient who is a compound heterozygote for two different CYP21 mutations is illustrated in Fig. 2.

Group C mutations predicted to confer relatively mild impairment of enzyme activity consisted of 10 nonclassic patients, 4 simple virilizing, and 2 patients with salt-wasting disease. Among the nonclassic patients with intron $2 \mathrm{~A} \rightarrow \mathrm{G} / \mathrm{Val}-$ $281 \rightarrow$ Leu, two unrelated patients, one male and one female, had a sevenfold difference in 17-hydroxyprogesterone levels 60 min after corticotropin stimulation (92 vs. $651 \mathrm{nmol} /$ liter).

Relationship of specific measures of in vivo 21-hydroxylase activity to mutation group. Mean basal serum 17-hydroxyprogesterone levels were significantly different among patients in mutation groups $\mathrm{A}, \mathrm{B}$, and $\mathrm{C}$ (mean $\pm \mathrm{SD}: 1,241 \pm 724$ vs $330 \pm 199$ and $229 \pm 372 \mathrm{nmol} /$ liter, $P=0.0001$, Fig. 3 ). A significant, but less striking, difference was also observed among groups when 60-min ACTH-stimulated levels were compared $(P=0.03)$. There were no significant differences between subgroups $A_{1}$ and $A_{2}$.

Fig. 4 shows the relationship of total phenotype score and component scores other than 17-hydroxyprogesterone (serum electrolytes and sodium balance, PRA/aldosterone, and Prader stage) to mutation group. A significant difference in total phenotype scores was evident among the three mutation groups ( $P=0.0001$ for mean \pm SD: $177 \pm 42$ vs. $125 \pm 56$ vs. $96 \pm 31$ in groups A, B, and C, respectively). Parallel differences were seen among mutation groups for each of the component scores, with the least significant difference observed in PRA/ aldosterone.

Discriminant analysis on the 56 patients who were eligible for inclusion based on four or more data points in the phenotype score yielded cut-off points as follows: group A if score $>123$; group $B$ if score $\geq 89$ and $\leq 123$; and group $C$ if score $<89$. This classification rule resulted in group $\mathrm{A}, \mathrm{B}$, and $\mathrm{C}$ patients being correctly classified 90,7 , and $58 \%$ of the time, respectively. The overall correct classification rate was $63 \%$. The rank transformed discriminant analysis yielded respective classification cut-off points of $>125,91$ to $<125$, and $<91$ for mutation groups $\mathrm{A}, \mathrm{B}$, and $\mathrm{C}$, respectively. The correct classification rates were 87,21 , and $58 \%$, respectively, with an overall correct classification rate of $64 \%$. Therefore, the effect of any outliers was minimal in this set of data. In contrast to phenotype score, the sensitivity of the clinical diagnoses (salt wasting, simple virilizing, and nonclassic) in correctly classifying patients into mutation groups $\mathrm{A}, \mathrm{B}$, or $\mathrm{C}$ was 90,71 , and $59 \%$, respectively. The overall correct classification rate for clinical diagnosis was $80 \%$. The relatively poor sensitivity of the phenotype score in correctly classifying individuals in mutation group B could be ameliorated by broadening the range of scores in which patients could be classified in this group, at the expense of decreased accuracy of classification into groups $\mathrm{A}$ and $\mathrm{C}$.

Data from sib pair studies. Four of five sib pairs classified as salt wasters in group A differed between sibs with respect to the ratio of PRA/aldosterone, sodium balance, or both. There were two additional families (Table V, group A, ID 43, group $B$, ID 16) in which the index case had acquired a de novo mutation, intron $2 \mathrm{~A} \rightarrow \mathrm{G}$, which was clearly not inherited from either mother or father, whose parental status was confirmed by HLA serotyping. In one of these families, the molecu- 


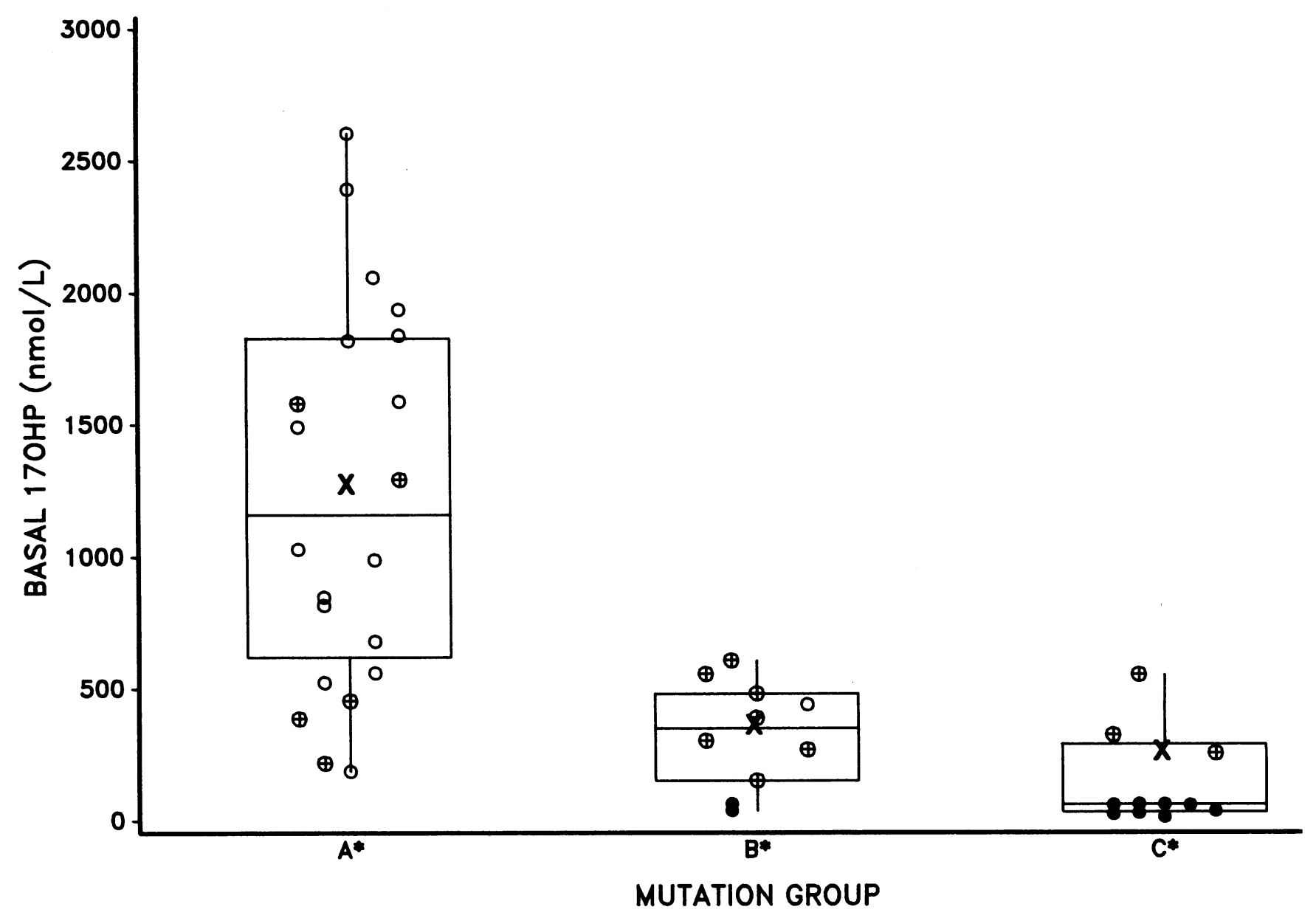

Figure 3. Relationship of serum 17-hydroxyprogesterone to mutation group. Basal serum levels of 17-hydroxyprogesterone (nmol/liter) were measured in the absence of glucocorticoid treatment at presentation in patients from each of the three mutation groups. Group $A$ includes the most severely deleterious mutations, group B are intermediate mutations, and group C are mild mutations. The box encompasses the 25-75th percentiles, the bar indicates the median, the cross indicates the mean, and the vertical lines indicate the ranges. Open circles designate saltwasting patients, crossed circles designate simple virilizing patients, and filled circles designate nonclassic patients. The asterisk indicates statistically significant differences between groups $(P=0.0001)$.

lar genetic data explained the apparent paradox of HLA identity in phenotypically dissimilar siblings, one of whom was affected with ambiguous genitalia and elevated 17-hydroxyprogesterone levels, whereas the second-born child was normal.

In group $\mathrm{B}$, the group with the widest range in phenotype scores, discordant clinical diagnoses were made in two of three genotypically identical sib pairs.

Finally, in one of three genotypically identical sib pairs in group C, the sister (Table V, group C, ID 1a) presented with normal genitalia and precocious adrenarche and subsequently developed severe hirsutism, whereas the brother (ID 2b) manifested no overt signs of his mild 21-hydroxylase deficiency through adolescence.

\section{Discussion}

Both methods of evaluating the clinical severity of disease, the clinical diagnosis and the phenotype score, were fairly well correlated with the degree of severity of the CYP21 mutation group. Thus, in vivo measures of 21-hydroxylase activity can to some extent be predicted from in vitro expression studies. Each mutation group contained a number of patients whose phenotype was either more or less severe than predicted. Several explanations might be proposed for these observations. First, it is conceivable that individuals with phenotypes more severe than predicted or discordant from siblings have acquired additional, as yet unidentified, mutations within the CYP21 gene. Undoubtedly, other mutations that may not have arisen from gene conversion will be identified, but based on knowledge accumulated to date these are probably less frequent than those already described.

Second, with respect to discrepancies between predicted and actual phenotypes, it should be recognized that the least impressive intergroup differences between mutation group and phenotypic expression were those found for PRA/aldosterone ratios. Nor did separate examination of aldosterone alone allow improved distinction between mutation groups $\mathrm{A}$ and $\mathrm{B}$, representing severely and moderately defective CYP21 genotype combinations, respectively. Based on data included in this and earlier reports (37), it is clear that patients with mutations conferring severe impairment of 21-hydroxylase activity have variable efficiency of aldosterone synthesis, even when the same patient is followed over time. In light of the variability in 


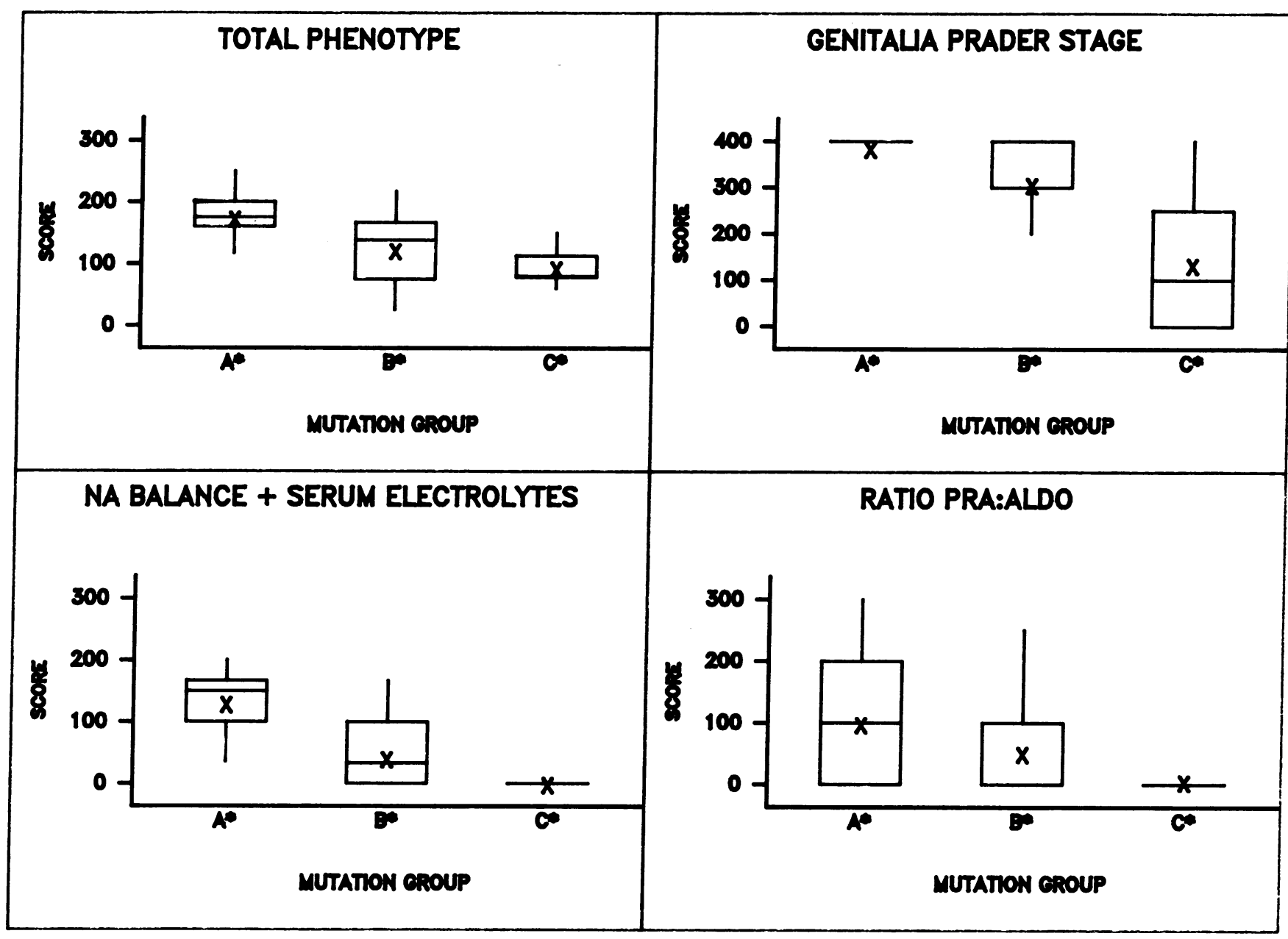

Figure 4. Relationship of phenotype score to mutation group. Adjusted phenotype scores (upper left) were calculated as described in the text. The other three panels show adjusted scores for the components of the total score, excluding 17-hydroxyprogesterone measurements. The box encompasses the 25-75th percentiles, the bar indicates the median, the cross indicates the mean, and the vertical lines indicate the ranges. Asterisks beside group letters show statistical differences between groups: $P=0.0001$ among mutation groups $\mathrm{A}, \mathrm{B}$, and $\mathrm{C}$ for total phenotype score, Prader stage, and sodium balance + serum electrolytes; $P=0.04$ among groups $\mathrm{A}, \mathrm{B}$, and $\mathrm{C}$ for the ratio of $\mathrm{PRA} /$ aldosterone $(A L D O)$.

aldosterone production and sodium homeostasis in genotypically identical siblings in this and an earlier report (34), it is plausible that at least some differences in clinical disease expression are governed by factors remote from the CYP21 locus.

Differences between salt-wasting and simple virilizing patients with respect to 17-hydroxyprogesterone levels may actually be more significant than is evident from this sample, since in three cases 17-hydroxyprogesterone levels were recorded as extremely high and were excluded from analysis because the levels were not precisely measured. Data on patients with severe, salt-wasting 21-hydroxylase deficiency are sparse because of the difficulty encountered in obtaining hormonal measurements in the absence of treatment. Some patients included in this study ( 13 salt-wasting and 6 simple virilizing) were born and diagnosed before the availability of radioimmunoassay for 17-hydroxyprogesterone. It is not clear why one salt-wasting infant had unusually low levels of 17-hydroxyprogesterone.

Third, some variations in phenotype may represent "leakiness" of the intron 2 splicing mutation, with $4 / 27$ patients in the $\mathrm{A}_{2}$ sub-group having been diagnosed as having simple virilizing disease. Splicing mutations have been associated with a variable degree of phenotypic severity when examined in thalas- semia (38). In vitro transcription of $\beta$-thalassemia genes carrying intronic mutations that activate cryptic splice acceptor sites show that the cells' splicing machinery recognizes cryptic splice acceptors with different frequencies and that some normally processed mRNA can result from such genes (39). The in vitro activity of CYP21 bearing the intron $2 \mathrm{~A} \rightarrow \mathrm{G}$ mutation has been examined in a single study, which indicated that the intronic mutation confers less severe enzymatic compromise than the Ile-172 $\rightarrow$ Asn mutation (36). It is not known whether this study, which involved transfection of cultured kidney epithelial cells, accurately describes in vivo activity. Precedent exists in at least one splicing mutation of the $\beta$-globin gene for finding an unexpectedly severe phenotype compared with the results of in vitro studies (40).

Finally, one might postulate that phenotypic severity is influenced by parental imprinting (41) or by negative allelic complementation, i.e., exaggerated gene dosage effect. Although there is no evidence of either of these phenomena from this sample, a larger number of families should be examined.

The molecular genetic epidemiology of 21-hydroxylase deficiency as described in this study is in good agreement with data from the single earlier study of point mutations in CYP2 1 
in which the genotypes of both parents have been examined (20). Knowledge of the specific molecular genetic defects in a given family should enhance the accuracy of prenatal diagnosis when compared with allele-specific oligonucleotide hybridization using class II HLA probes, which carries an inherent error rate of $\geq 1 \%$ because of recombination between the HLA-DR locus and CYP21.

In conclusion, we have demonstrated with careful clinical and hormonal evaluations of patients that the severity of clinical disease generally correlates with what might be expected based on in vitro expression studies of discrete mutations. However, in each of the three mutation groups there were patients whose phenotype was different from that predicted, the reason for which is not immediately obvious and requires further investigation. In contrast to conclusions drawn by Okano et al. (42) in a recent elegant study of phenotype-genotype correlations in phenylketonuria, we are less certain that knowing the genotype will absolutely predict the course of the disease. Because of the observed discordance between phenotype and genotype in each mutation group, we believe that clinicians would be ill-advised to make therapeutic decisions based on genotype or to predict clinical outcome in a second-born affected child based on data gleaned from an older sibling. We advocate careful hormonal studies at presentation and periodically throughout childhood and adolescence to optimize therapy for each patient. Further studies of genetically identical sibling pairs may illuminate the source(s) of individual variability in phenotype. The relatively high rate of new mutations observed in this small sample $(\sim 1 \%)$ should be further examined in a larger series of families.

\section{Acknowledgments}

We thank the staff of the Children's Clinical Research Center for their expert assistance in performing hormonal testing in patients, Dr. Arlene Mercado for assistance in data and sample collection, Jiri Vitek and Dr. Jihad Obeid for data organization, Mrs. Vita Amendolagine for assistance in manuscript preparation, and Dr. Joseph Gertner for critical reading of the manuscript. We also thank the many physicians who have referred the patients included in these studies.

This work was supported by grants HD-00072, DK-37867, RR-47, and RR-06020 from the National Institutes of Health and by a grant from the Horace Goldsmith Foundation. P. C. White is an Irma Hirschl Trust Scholar.

\section{References}

1. New, M. I., P. C. White, S. Pang, B. Dupont, and P. W. Speiser. 1989. The adrenal hyperplasias. In The Metabolic Basis of Inherited Disease. 6th ed. C. R. Scriver, A. L. Beaudet, W. S. Sly, and D. Valle, editors. McGraw-Hill, New York. 1881-1917.

2. White, P. C., M. I. New, and B. Dupont. 1986. Structure of human steroid 21-hydroxylase genes. Proc. Natl. Acad. Sci. USA. 83:5111-5115.

3. Higashi, Y., H. Yoshioka, M. Yamane, O. Gotoh, and Y. Fujii-Kuriyama. 1986. Complete nucleotide sequence of two steroid 21-hydroxylase genes tandemly arranged in human chromosome: a pseudogene and a genuine gene. Proc. Natl. Acad. Sci. USA. 83:2841-2845.

4. Dupont, B., S. E. Oberfield, E. M. Smithwick, T. D. Lee, and L. S. Levine. 1977. Close genetic linkage between HLA and congenital adrenal hyperplasia (21-hydroxylase deficiency). Lancet. 2:1309-1311.

5. Levine, L. S., M. Zachmann, M. I. New, A. Prader, M. S. Pollack, G. J. O'Neill, S. Y. Yang, S. E. Oberfield, and B. Dupont. 1978. Genetic mapping of the 21-hydroxylase-deficiency gene within the HLA linkage group. $N$. Engl. J. Med. 299:911-915.

6. White, P. C., A. Vitek, B. Dupont, and M. I. New. 1988. Characterization of frequent deletions causing steroid 21-hydroxylase deficiency. Proc. Natl. Acad. Sci. USA. 85:4436-4440.
7. Amor, M., K. L. Parker, H. Globerman, M. I. New, and P. C. White. 1988 A mutation in the CYP21B gene (ILE 172 to ASN 172) causes steroid 21-hydroxylase deficiency. Proc. Natl. Acad. Sci. USA. 85:1600-1604.

8. Globerman, H., M. Amor, K. L. Parker, M. I. New, and P. C. White. 1988 A nonsense mutation causing steroid 21-hydroxylase deficiency. J. Clin. Invest. 82:139-144.

9. White, P. C. 1989. Analysis of mutations causing steroid 21-hydroxylase deficiency. Endocr. Res. 15:239-256.

10. Strachan, T. 1990. Molecular pathology of congenital adrenal hyperplasia. Clin. Endocrinol. 32:373-393.

11. Kuhnle, U., D. Chow, R. Rapaport, S. Pang, L. S. Levine, and M. I. New. 1981. The 21-hydroxylase activity in the glomerulosa and fasciculata of the adrenal cortex in congenital adrenal hyperplasia. J. Clin. Endocrinol. Metab. 52:534544.

12. Kohn, B., L. S. Levine, M. S. Pollack, S. Pang, F. Lorenzen, D. Levy, A Lerner, G. F. Rondanini, B. Dupont, and M. I. New. 1982. Late-onset steroid 21-hydroxylase deficiency: a variant of classical congenital adrenal hyperplasia. J. Clin. Endocrinol. Metab. 55:817-827.

13. Collier, S., P. J. Sinnott, P. A. Dyer, D. A. Price, R. Harris, and T. Strachan. 1989. Pulsed field gel electrophoresis identifies a high degree of variability in the number of tandem 21-hydroxylase and complement C4 gene repeats in 21-hydroxylase deficiency haplotypes. EMBO (Eur. Mol. Biol. Organ.) J. 8:1393-1402.

14. Partanen, J., S. Koskimies, I. Sipila, and V. Lipsanen. 1989. Major-histocompatibility-complex gene markers and restriction-fragment analysis of steroid 21-hydroxylase (CYP21) and complement C4 genes in classical congenital adrenal hyperplasia patients in a single population. Am. J. Hum. Genet. 44:660-670.

15. White, P. C., M. I. New, and B. Dupont. 1984. HLA-linked congenital adrenal hyperplasia results from a defective gene encoding a cytochrome $\mathrm{P}-450$ specific for steroid 21-hydroxylation. Proc. Natl. Acad. Sci. USA. 81:7505-7509.

16. Morel, Y., J. Andre, B. Uring-Lambert, G. Hauptmann, H. Betuel, M. Tossi, M. G. Forest, M. David, J. Bertrand, and W. L. Miller. 1989. Rearrangements and point mutations of $P 450 \mathrm{c} 21$ genes are distinguished by five restriction endonuclease haplotypes identified by a new probing strategy in 57 families with congenital adrenal hyperplasia. J. Clin. Invest. 83:527-536.

17. Speiser, P. W., M. I. New, and P. C. White. 1988. Molecular genetic analysis of nonclassic steroid 21-hydroxylase deficiency associated with HLAB14,DR1. N. Engl. J. Med. 319:19-23.

18. Higashi, Y., A. Tanae, H. Inoue, T. Hiromasa, and Y. Fujii-Kuriyama. 1988. Aberrant splicing and missense mutations cause steroid 21-hydroxylase [P-450(C21)] deficiency in humans: possible gene conversion products. Proc. Natl. Acad. Sci. USA. 85:7486-7490.

19. Owerbach, D., Y. M. Crawford, and M. B. Draznin. 1990. Direct analysis of CYP21B genes in 21-hydroxylase deficiency using polymerase chain reaction amplification. Mol. Endocrinol. 4:125-131.

20. Mornet, E., P. Crete, F. Kuttenn, M.-C. Raux-Demay, J. Boue, P. C. White, A. Boue. 1991. Distribution of deletions and seven point mutations on CYP21B genes in three clinical forms of steroid 21-hydroxylase deficiency. Am.J. Hum. Genet. 48:79-88.

21. Pang, S., J. Hotchkiss, A. L. Drash, L. S. Levine, and M. I. New. 1977. Microfilter paper method for 17a-hydroxyprogesterone radioimmunoassay: its application for rapid screening for congenital adrenal hyperplasia. J. Clin. Endocrinol. Metab. 45:1003-1008.

22. Korth-Schutz, S., R. Virdis, P. Saenger, D. M. Chow, L. S. Levine, and M. I. New. 1978. Serum androgens as a continuing index of adequacy of treatment of congenital adrenal hyperplasia. J. Clin. Endocrinol. Metab. 46:452-458.

23. Rauh, W., L. S. Levine, K. Gottesdiener, and M. I. New. 1978. Mineralocorticoids, salt balance and blood pressure after prolonged ACTH administration in juvenile hypertension. Klin. Wochenschr. 66(Suppl I):161-167.

24. New, M. I., F. Lorenzen, A. J. Lerner, B. Kohn, S. E. Oberfield, M. S. Pollack, B. Dupont, E. Stoner, D. J. Levy, S. Pang, et al. 1983. Genotyping steroid 21-hydroxylase deficiency: hormonal reference data. J. Clin. Endocrinol. Metab. 57:320-326.

25. Charmakjian, Z. H., W. W. Pryor, and G. E. Abraham. 1974. A radioimmunoassay for serum and urine aldosterone by celite column chromatography. Anal. Lett. 7:97-108.

26. Luetscher, J. A., A. J. Dowdy, A. M. Callaghan, and A. P. Cohn. 1962. Studies of secretion and metabolism of aldosterone and cortisol. Trans. Assoc. Am. Physicians. 75:293-300.

27. New, M. I., B. Miller, and R. E. Peterson. 1966. Aldosterone excretion in normal children and in children with adrenal hyperplasia. J. Clin. Invest. 45:412428.

28. Preibisz, J. J., J. E. Sealey, R. M. Aceto, J. H. Laragh. 1982. Plasma renin activity measurements: an update. Cardiovasc. Rev. Rep. 3:787-804.

29. Prader, V. A. 1958. Vollkommen Manliche außere Genitaletwicklung und Salzverlustsyndrom bei Madchen mit Kongenitalem adrenogenitalem Syndrom. Helv. Paediatr. Acta. 13:5-14.

30. Wyman, A. R., and R. White. 1980. A highly polymorphic locus in human DNA. Proc. Natl. Acad. Sci. USA. 77:6754-6758. 
31. Johns, M. B., and J. E. Paulus-Thomas. 1989. Purification of human genomic DNA from whole blood using sodium perchlorate in place of phenol. Anal. Biochem. 180:276-278.

32. Tusie-Luna, M. T., P. W. Speiser, M. Dumic, M. I. New, and P. C. White. 1991. A mutation (Pro-30 to Leu) in CYP21 represents a potential nonclassic steroid 21-hydroxylase deficiency allele. Mol. Endocrinol. 5:685-692.

33. Pang, S., M. A. Wallace, L. Hofman, H. C. Thuline, C. Dorche, I. C. T. Lyon, R. H. Dobbins, S. Kling, K. Fujieda, and S. Suwa. 1988. Worldwide experience in newborn screening for classical congenital hyperplasia due to 21 -hydroxylase deficiency. Pediatrics. 81:866-874.

34. Stoner, E., J. Dimartino-Nardi, U. Kuhnle, L. S. Levine, S. E. Oberfield, and M. I. New. 1986. Is salt-wasting in congenital adrenal hyperplasia due to the same gene as the fasciculata defect? Clin. Endocrinol. 24:9-20.

35. Tusie-Luna, M.-T., P. Traktman, and P. C. White. 1990. Determination of functional effects of mutations in the steroid 21-hydroxylase gene (CYP21) using recombinant vaccinia virus. J. Biol. Chem. 265:20916-20922.

36. Higashi, Y., T. Hiromasa, A. Tanae, T. Miki, J. Nakura, T. Kondo, T. Ohura, E. Ogawa, K. Nakayama, and Y. Fujii-Kurayama. 1991. Effects of individual mutations in the P-450(C21) pseudogene on the P-450(C21) activity and their distribution in the patient genomes of congenital steroid 21-hydroxylase deficiency. J. Biochem. 109:638-644.

37. Speiser, P. W., L. Agdere, H. Ueshiba, P. C. White, and M. I. New. 1991. Aldosterone synthesis in salt-wasting congenital adrenal hyperplasia with complete absence of adrenal 21-hydroxylase. N. Engl. J. Med. 324:145-149.

38. Loukopoulos, D. 1991. Thalassemia: genotypes and phenotypes. Ann. Hematol. 62:85-94.

39. Treisman, R., S. H. Orkin, and T. Maniatis. 1983. Specific transcription and RNA splicing defects in five cloned $\beta$-thalassemia genes. Nature (Lond.). 302:591-596.

40. Wong, C., S. E. Antonarakis, S. C. Goff, S. H. Orkin, B. G. Forget, D. G. Nathan, P. J. Giardina, and H. H. Kazazian, Jr. 1989. Beta-thalassemia due to two novel nucleotide substitutions in consensus acceptor splice sequences of the beta-globin gene. Blood. 73:914-918.

41. Hall, J. G. 1990. How imprinting is relevant to human disease. Development (Camb.). (Suppl.) 141-148.

42. Okano, Y., R. C. Eisensmith, F. Guttler, U. Lichter-Konecki, D. S. Konecki, F. K. Trefz, M. Dasovich, T. Wang, K. Henriksen, H. Lou, et al. 1991. Molecular basis of phenotypic heterogeneity in phenylketonuria. N. Engl. J. Med. 324:1232-1238. 